\title{
The acute effect of cold pack applied for different periods on the biomechanical properties of the rectus femoris muscle of healthy individuals: a randomized experimental study
}

Nuray ALACA ( $\nabla$ nuray.alaca@acibadem.edu.tr )

Acıbadem University https://orcid.org/0000-0003-3034-9388

Nilüfer Kablan

health sciences university

Research article

Keywords: Cold pack, temperature, stiffness, tone, elasticity

Posted Date: June 30th, 2020

DOI: https://doi.org/10.21203/rs.3.rs-30726/v2

License: (a) This work is licensed under a Creative Commons Attribution 4.0 International License.

Read Full License 
The authors have withdrawn this preprint from Research Square 